\title{
Evolution of the importance of neutron-induced reactions along the cycle of an LFR
}

\author{
Pablo Romojaro ${ }^{1, *}$ and Francisco Álvarez-Velarde ${ }^{1, * *}$ \\ ${ }^{1}$ Centro de investigaciones Energéticas, Medioambientales y Tecnológicas (CIEMAT), Energy Department, Avda. Complutense 40, \\ 28040 Madrid, Spain
}

\begin{abstract}
The Lead-cooled Fast Reactor is one of the three technologies selected by the Sustainable Nuclear Energy Technology Platform that can meet future European energy needs. Several LFR concepts are now in design phase, such as MYRRHA and ALFRED, and accurate nuclear data are required for the neutronic and safety assessment of the fast reactor designs. In this work, an assessment of the evolution of the importance of neutron-induced reactions along the cycle of a reference LFR design (i.e., ALFRED) with the state-of-the-art JEFF-3.3 nuclear data library is performed. Sensitivity analyses have been carried out with MCNP6 code in order to identify the most relevant isotopes and reactions from the neutronic point of view at BoL, BoC and EoC. Furthermore, an uncertainty quantification has been performed with the SUMMON system to study the evolution of uncertainties in the $k_{\text {eff }}$ along the reactor cycle. The results from this work provide an exhaustive picture on the influence of nuclear data on core criticality performance, identifying key quantities and nuclear data needs relevant to achieve an improved safety level for LFR.
\end{abstract}

\section{Introduction}

The Gen-IV International Forum [1] has identified and selected six nuclear energy systems for further research and development that can help meet the world's future energy needs. In parallel, Europe with the European Sustainable Nuclear Industrial Initiative [2] has chosen three Gen-IV fast reactor technologies as candidates that can satisfy future European energy demands: the sodium-cooled fast reactors (SFR), the lead-cooled fast reactors (LFR) and the gas-cooled fast reactors (GFR). Several LFR concepts are now in design phase in Europe, such as the Multipurpose hYbrid Research Reactor for High-tech Applications (MYRRHA) [3] and the Advanced Lead-cooled Fast Reactor European Demonstrator (ALFRED) [4]. For the design and safety assessment of these advanced nuclear systems, accurate nuclear data are of fundamental importance [5]. In this paper, an assessment of the evolution of the importance of neutron-induced reactions along the cycle of a reference LFR design (i.e., ALFRED) with the state-of-the-art JEFF-3.3 nuclear data library [6] has been performed to identify possible nuclear data needs. Sensitivity analyses have been carried out with MCNP6 code [7] in order to derive the most relevant isotopes and reactions from the neutronic point of view at Beginning of Life (BoL), Beginning of Cycle $(\mathrm{BoC})$ and End of $\mathrm{Cy}-$ cle $(\mathrm{EoC})$. Furthermore, an uncertainty quantification has been performed with the SUMMON system $[8,9]$ to study the evolution of uncertainties in the effective neutron multiplication factor along the reactor cycle.

\footnotetext{
*e-mail: pablo.romojaro@ciemat.es

**e-mail: francisco.alvarez@ciemat.es
}

\subsection{ALFRED reactor}

ALFRED is a $300 \mathrm{MWth}$ small-size pool type reactor cooled by lead, with the core, primary pumps and steam generators contained within the reactor vessel. It shall be connected to the electrical grid (125 MWe) and use already available technology to speed up construction time, with corrosion-resistant structural materials compatible with lead. ALFRED core, as shown in Fig. 1, is composed by 171 hexagonal fuel assemblies divided in an inner and an outer zone, with different plutonium enrichments (higher enrichment in the outer region) to flatten the power distribution. Regarding the fuel management strategy pursued in ALFRED, it is a 5 years fuel residence time (in order to achieve $100 \mathrm{MWd} / \mathrm{kgHM}$ as peak burn up), with $1 / 5$ of the core unloaded every year and replaced by fresh fuel. Three models of ALFRED at BoL, BoC and EoC have been developed for MCNP6 code according to the specifications given in Ref. [10], which taking into account the assumed fuel management strategy, correspond to start-up, 2 years of burn up and 3 years of fuel burn up, respectively.

\section{SUMMON}

The Sensitivity and Uncertainty Methodology for MONtecarlo codes (SUMMON) system has been conceived by CIEMAT as a tool to perform complete automated sensitivity and uncertainty analyses of the most relevant criticality safety parameters of detailed complex reactor designs from the neutronic point of view, i.e., $k_{e f f}, \beta_{e f f}$, $\Lambda_{\text {eff }}$ and reactivity coefficients, using state-of-the-art nuclear data libraries and covariances. The methodology is 


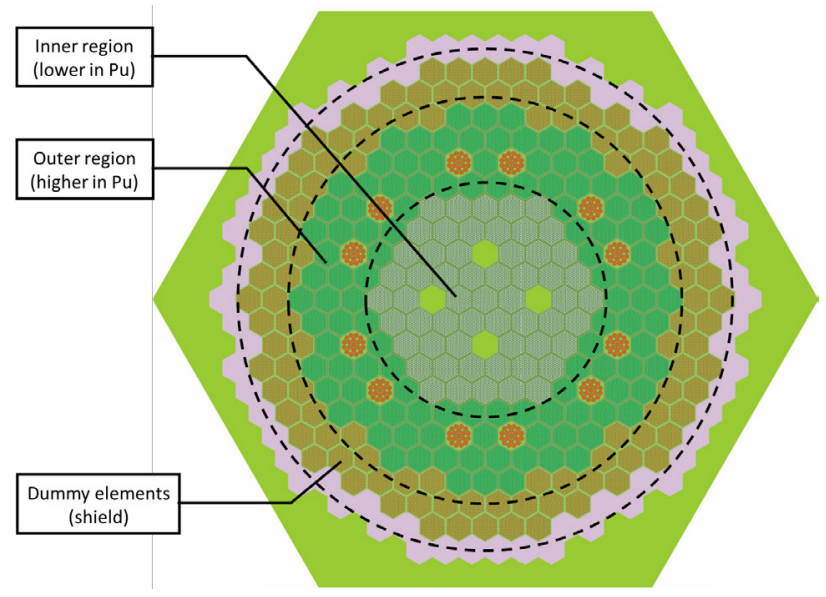

Figure 1. ALFRED core model.

based on the use of the KSEN card of MCNP6 code to perform the eigenvalue sensitivity calculations, although any code that can provide sensitivity coefficients can be used. The sensitivity coefficients of a reactivity response are calculated using the eigenvalue definition of reactivity, which is equivalent to applying the Equivalent Generalized Perturbation Theory [11]. Moreover, the effective delayed neutron fraction sensitivity coefficients are derived from Bretscher's approximation [12] or employing Chiba's modified method [13], whereas the sensitivity coefficients of the effective neutron generation time are obtained using the 1 / v insertion method [14] and the Equivalent Generalized Perturbation Theory. Uncertainties are propagated using the "Sandwich Rule" of the "Propagation of Moments" method employing covariance data from state-of-the-art covariance libraries. A detailed description of SUMMON, including the methodologies used to calculate the sensitivity coefficients and perform the uncertainty quantification analyses, together with the validation and verification tests carried out, can be found in Ref. [8, 9].

\section{Sensitivity analysis}

Results from the sensitivity calculations performed at BoL, BoC and EoC using the JEFF-3.3 library are presented in Table 1. It can be seen that, for $k_{\text {eff }}$, the most important isotopes are the ones in the fuel and the coolant, and that the ranking of importance is maintained while the fuel is burned. Nevertheless, there are changes in the sensitivity of $k_{e f f}$ to some quantities (i.e., isotope and reaction). These differences can be explained by the evolution of the inventory with the burn up; e.g., ${ }^{239} \mathrm{Pu}$ and ${ }^{240} \mathrm{Pu}$ content increases more than ${ }^{241} \mathrm{Pu}$, therefore there are more fissions taking place on ${ }^{239} \mathrm{Pu}$ and ${ }^{240} \mathrm{Pu}$ and, consequently, the sensitivity to ${ }^{241} \mathrm{Pu}(\mathrm{n}, \mathrm{f})$ decreases while the sensitivity to ${ }^{239} \mathrm{Pu}(\mathrm{n}, \mathrm{f})$ and ${ }^{240} \mathrm{Pu}(\mathrm{n}, \mathrm{f})$ increases. Likewise, differences can be observed in the elastic scattering of ${ }^{208} \mathrm{~Pb}$ and ${ }^{16} \mathrm{O}$ which can be attributed to differences in the spectrum, caused once again by differences in the inventory due to the burn up.
Table 1. Top 15 Integrated Sensitivity Coefficients for ALFRED and different reactor cycles. The statistical uncertainty of the sensitivity coefficients due to Monte Carlo calculations is $10^{-5}$.

\begin{tabular}{llrrr}
\hline Nuclide & Reaction & \multicolumn{1}{c}{ BoL } & \multicolumn{1}{c}{ BoC } & \multicolumn{1}{c}{ EoC } \\
& & \multicolumn{1}{c}{$S_{k_{\text {eff }}}$} & \multicolumn{1}{c}{$S_{k_{\text {eff }}}$} & \multicolumn{1}{c}{$S_{k_{\text {eff }}}$} \\
\hline${ }^{239} \mathrm{Pu}$ & $v_{\mathrm{p}}$ & 0.686 & 0.688 & 0.690 \\
${ }^{239} \mathrm{Pu}$ & $(\mathrm{n}, \mathrm{f})$ & 0.482 & 0.496 & 0.498 \\
${ }^{238} \mathrm{U}$ & $(\mathrm{n}, \gamma)$ & -0.149 & -0.145 & -0.147 \\
${ }^{241} \mathrm{Pu}$ & $v_{\mathrm{p}}$ & 0.102 & 0.093 & 0.091 \\
${ }^{238} \mathrm{U}$ & $v_{\mathrm{p}}$ & 0.081 & 0.084 & 0.083 \\
${ }^{240} \mathrm{Pu}$ & $v_{\mathrm{p}}$ & 0.077 & 0.081 & 0.082 \\
${ }^{241} \mathrm{Pu}$ & $(\mathrm{n}, \mathrm{f})$ & 0.073 & 0.068 & 0.067 \\
${ }^{240} \mathrm{Pu}$ & $(\mathrm{n}, \mathrm{f})$ & 0.052 & 0.056 & 0.057 \\
${ }^{238} \mathrm{U}$ & $(\mathrm{n}, \mathrm{f})$ & 0.049 & 0.052 & 0.051 \\
${ }^{239} \mathrm{Pu}$ & $(\mathrm{n}, \gamma)$ & -0.047 & -0.045 & -0.046 \\
${ }^{238} \mathrm{U}$ & $(\mathrm{n}, \mathrm{n})$ & -0.034 & -0.037 & -0.036 \\
${ }^{208} \mathrm{~Pb}$ & $(\mathrm{n}, \mathrm{n})$ & 0.028 & 0.034 & -0.035 \\
${ }^{16} \mathrm{O}$ & $(\mathrm{n}, \mathrm{n})$ & -0.027 & -0.031 & 0.034 \\
${ }^{240} \mathrm{Pu}$ & $(\mathrm{n}, \gamma)$ & -0.025 & -0.025 & -0.026 \\
${ }^{238} \mathrm{Pu}$ & $v_{\mathrm{p}}$ & 0.018 & 0.017 & 0.017 \\
\hline
\end{tabular}

However, it is important to note that these differences are on the same order of magnitude than the differences that can be obtained if we used a different code or a different library and repeated the analyses [15]. Therefore, it can be considered that the most important nuclear data, from $k_{\text {eff }}$ point of view, is the same along the reactor cycles.

\section{Uncertainty quantification}

In order to study the impact in the uncertainty in $k_{\text {eff }}$ of the differences obtained in the sensitivity analysis, an uncertainty quantification using JEFF-3.3 covariance data has been performed (Table2). A slight increase in the total uncertainty in $k_{\text {eff }}$ can be observed due to the burn up and the appearance of fission products and other transuranium elements in the fuel, which introduce new sources of uncertainty. Additionally, the uncertainty in the major contributors slightly changes with the burn up, once more, due to the evolution of the inventory. While the most important contributor is the fission of ${ }^{240} \mathrm{Pu}$ in the three reactor cycles, this quantity was not the highest ranked one in the sensitivity analyses, which denotes that the uncertainty in ${ }^{240} \mathrm{Pu}(\mathrm{n}, \mathrm{f})$ cross section in the energy range of interest $(0.1$ $\mathrm{keV}-4 \mathrm{MeV})$ is high. Indeed, an uncertainty of nearly $35 \%$ in that energy range can be observed for ${ }^{240} \mathrm{Pu}(\mathrm{n}, \mathrm{f})$ cross section in Fig. 2.

On the other hand, ${ }^{239} \mathrm{Pu}$ presents the opposite behaviour, with an uncertainty not higher than $4 \%$ in the same energy range. The impact of these evaluations is reflected in the uncertainty analysis, i.e., while the sensitivity of $k_{\text {eff } f}$ to ${ }^{239} \mathrm{Pu}(\mathrm{n}, \mathrm{f})$ is one order of magnitude higher than the sensitivity to ${ }^{240} \mathrm{Pu}(\mathrm{n}, \mathrm{f})$, the high uncertainty of ${ }^{240} \mathrm{Pu}(\mathrm{n}, \mathrm{f})$ cross section makes this quantity the most important contributor, in spite of its lower sensitivity. This indicates that, if a reduction in the total uncertainty in $k_{e f f}$ is desired (i.e., higher accuracy in $k_{e f f}$ ), the uncertainty in 
Table 2. $k_{e f f}$ uncertainty quantification for ALFRED at BoL, BoC and EoC with JEFF-3.3.

\begin{tabular}{|c|c|c|c|c|c|c|}
\hline \multicolumn{7}{|c|}{$\Delta k_{e f f} / k_{e f f}(\% / \%)-$ JEFF.3.3 } \\
\hline \multicolumn{4}{|c|}{ Quantity } & BoL & $\mathrm{BoC}$ & EoC \\
\hline${ }^{240} \mathrm{Pu}$ & $(\mathrm{n}, \mathrm{f})$ & ${ }^{240} \mathrm{Pu}$ & $(\mathrm{n}, \mathrm{f})$ & 0.524 & 0.572 & 0.586 \\
\hline${ }^{240} \mathrm{Pu}$ & $(\mathrm{n}, \mathrm{f})$ & ${ }^{240} \mathrm{Pu}$ & $(\mathrm{n}, \gamma)$ & -0.421 & -0.441 & -0.455 \\
\hline${ }^{239} \mathrm{Pu}$ & $v_{\mathrm{p}}$ & ${ }^{239} \mathrm{Pu}$ & $v_{\mathrm{p}}$ & 0.318 & 0.319 & 0.320 \\
\hline${ }^{239} \mathrm{Pu}$ & $(\mathrm{n}, \mathrm{f})$ & ${ }^{239} \mathrm{Pu}$ & $(\mathrm{n}, \mathrm{f})$ & 0.296 & 0.307 & 0.314 \\
\hline${ }^{239} \mathrm{Pu}$ & $\chi$ & ${ }^{239} \mathrm{Pu}$ & $\chi$ & 0.292 & 0.306 & 0.295 \\
\hline${ }^{238} \mathrm{U}$ & $\left(\mathrm{n}, \mathrm{n}^{\prime}\right)$ & ${ }^{238} \mathrm{U}$ & $\left(\mathrm{n}, \mathrm{n}^{\prime}\right)$ & 0.234 & 0.254 & 0.246 \\
\hline${ }^{238} \mathrm{U}$ & $(\mathrm{n}, \gamma)$ & ${ }^{238} \mathrm{U}$ & $(\mathrm{n}, \gamma)$ & 0.230 & 0.224 & 0.224 \\
\hline${ }^{240} \mathrm{Pu}$ & $(\mathrm{n}, \gamma)$ & ${ }^{240} \mathrm{Pu}$ & $(\mathrm{n}, \gamma)$ & 0.206 & 0.207 & 0.215 \\
\hline${ }^{238} \mathrm{U}$ & $\left(\mathrm{n}, \mathrm{n}^{\prime}\right)$ & ${ }^{238} \mathrm{U}$ & $(\mathrm{n}, \mathrm{f})$ & -0.192 & -0.205 & -0.200 \\
\hline${ }^{239} \mathrm{Pu}$ & $(\mathrm{n}, \mathrm{f})$ & ${ }^{239} \mathrm{Pu}$ & $(\mathrm{n}, \gamma)$ & 0.188 & 0.185 & 0.185 \\
\hline${ }^{238} \mathrm{U}$ & $\left(\mathrm{n}, \mathrm{n}^{\prime}\right)$ & ${ }^{238} \mathrm{U}$ & $(\mathrm{n}, \gamma)$ & 0.169 & 0.175 & 0.175 \\
\hline${ }^{238} \mathrm{U}$ & $(n, f)$ & ${ }^{238} \mathrm{U}$ & $(\mathrm{n}, \gamma)$ & 0.141 & 0.143 & 0.141 \\
\hline${ }^{206} \mathrm{~Pb}$ & $\left(\mathrm{n}, \mathrm{n}^{\prime}\right)$ & ${ }^{206} \mathrm{~Pb}$ & $\left(\mathrm{n}, \mathrm{n}^{\prime}\right)$ & 0.140 & 0.149 & 0.149 \\
\hline${ }^{239} \mathrm{Pu}$ & $(\mathrm{n}, \gamma)$ & ${ }^{239} \mathrm{Pu}$ & $(\mathrm{n}, \gamma)$ & 0.137 & 0.130 & 0.132 \\
\hline${ }^{238} \mathrm{U}$ & $(\mathrm{n}, \mathrm{f})$ & ${ }^{238} \mathrm{U}$ & $(\mathrm{n}, \mathrm{f})$ & 0.123 & 0.131 & 0.128 \\
\hline \multicolumn{4}{|c|}{ Total uncertainty in $k_{e f f}$} & 0.788 & 0.824 & 0.826 \\
\hline
\end{tabular}

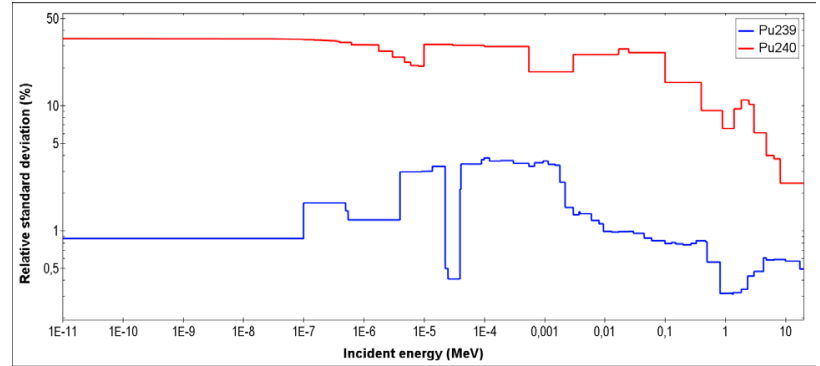

Figure 2. Relative standard deviation of ${ }^{239} \mathrm{Pu}$ and ${ }^{240} \mathrm{Pu}$ fission cross section in JEFF-3.3.

${ }^{240} \mathrm{Pu}(\mathrm{n}, \mathrm{f})$ cross section in JEFF-3.3 must be reduced. Furthermore, it is important to notice that uncertainty analyses are strongly dependent on the input evaluated covariance data used. To study the dependence of the total uncertainty in $k_{\text {eff }}$ with state-of-the-art evaluations, an additional uncertainty analysis has been performed with ENDF/B-VIII.0 nuclear data library [16] for ALFRED at BoC (Table 3). It can be seen that, even if the global uncertainty agrees with the one predicted by JEFF-3.3 (Table 2), the contributors and the magnitude of the contribution to that uncertainty strongly differ. These differences can attributed to differences in the uncertainty evaluations, such as the case of ${ }^{208} \mathrm{~Pb}(\mathrm{n}, \mathrm{n}$ '); to missing correlations, such as ${ }^{240} \mathrm{Pu}(\mathrm{n}, \mathrm{f})-{ }^{240} \mathrm{Pu}(\mathrm{n}, \gamma)$ in the fast energy range for ENDF/B-VIII.0; and to missing covariance evaluations, such as 242Am in JEFF-3.3, which, should they be taken into account, would make the total uncertainty increase.

Moreover, the design target accuracy for $k_{\text {eff }}$ of 300 pcm for fast reactors, established in 2008 by SG-26 of the Working Party on International Nuclear Data Evaluation Co-operation of OECD/NEA [17], is exceeded by more than a factor of two with both nuclear data libraries. Therefore, uncertainty in nuclear data must be reduced to meet the target accuracy for $k_{e f f}$.
Table 3. $k_{\text {eff }}$ uncertainty quantification for ALFRED at BoC with ENDF/B-VIII.0.

\begin{tabular}{|c|c|c|c|c|}
\hline \multicolumn{5}{|c|}{$\Delta k_{e f f} / k_{e f f}(\% / \%)-$ JEFF.3.3 } \\
\hline \multicolumn{3}{|c|}{ Quantity } & \multicolumn{2}{|c|}{ BoC } \\
\hline${ }^{239} \mathrm{Pu}$ & $(\mathrm{n}, \mathrm{f})$ & ${ }^{239} \mathrm{Pu}$ & $(\mathrm{n}, \mathrm{f})$ & 0.577 \\
\hline${ }^{239} \mathrm{Pu}$ & $(\mathrm{n}, \gamma)$ & ${ }^{239} \mathrm{Pu}$ & $(\mathrm{n}, \gamma)$ & 0.214 \\
\hline${ }^{239} \mathrm{Pu}$ & $v_{\mathrm{p}}$ & ${ }^{239} \mathrm{Pu}$ & $v_{\mathrm{p}}$ & 0.187 \\
\hline${ }^{238} \mathrm{U}$ & $(\mathrm{n}, \gamma)$ & ${ }^{238} \mathrm{U}$ & $(\mathrm{n}, \gamma)$ & 0.186 \\
\hline${ }^{239} \mathrm{Pu}$ & $x$ & ${ }^{239} \mathrm{Pu}$ & $\chi$ & 0.153 \\
\hline${ }^{238} \mathrm{U}$ & $v_{\mathrm{T}}$ & ${ }^{238} \mathrm{U}$ & $v_{\mathrm{p}}$ & 0.151 \\
\hline${ }^{238} \mathrm{U}$ & $\left(\mathrm{n}, \mathrm{n}^{\prime}\right)$ & ${ }^{238} \mathrm{U}$ & $(\mathrm{n}, \mathrm{f})$ & -0.142 \\
\hline${ }^{238} \mathrm{U}$ & $\left(\mathrm{n}, \mathrm{n}{ }^{\prime}\right)$ & ${ }^{238} \mathrm{U}$ & $\left(\mathrm{n}, \mathrm{n}^{\prime}\right)$ & 0.130 \\
\hline${ }^{238} \mathrm{U}$ & $\left(\mathrm{n}, \mathrm{n}{ }^{\prime}\right)$ & ${ }^{238} \mathrm{U}$ & $(\mathrm{n}, \gamma)$ & 0.127 \\
\hline${ }^{238} \mathrm{U}$ & $v_{\mathrm{p}}$ & ${ }^{238} \mathrm{U}$ & $v_{\mathrm{p}}$ & 0.107 \\
\hline${ }^{208} \mathrm{~Pb}$ & $(\mathrm{n}, \mathrm{n})$ & ${ }^{208} \mathrm{~Pb}$ & $(\mathrm{n}, \mathrm{n})$ & 0.100 \\
\hline${ }^{240} \mathrm{Pu}$ & $(\mathrm{n}, \gamma)$ & ${ }^{240} \mathrm{Pu}$ & $(\mathrm{n}, \gamma)$ & 0.092 \\
\hline${ }^{240} \mathrm{Pu}$ & $\chi$ & ${ }^{240} \mathrm{Pu}$ & $\chi$ & 0.087 \\
\hline${ }^{56} \mathrm{Fe}$ & $(\mathrm{n}, \gamma)$ & ${ }^{56} \mathrm{Fe}$ & $(\mathrm{n}, \gamma)$ & 0.081 \\
\hline${ }^{206} \mathrm{~Pb}$ & $\left(\mathrm{n}, \mathrm{n}{ }^{\prime}\right)$ & ${ }^{206} \mathrm{~Pb}$ & $(\mathrm{n}, \mathrm{n}$ ') & 0.074 \\
\hline \multicolumn{3}{|c|}{ Total uncertainty in $k_{e f f}$} & 0.746 & \\
\hline
\end{tabular}

\section{Conclusions}

The influence of nuclear data on the criticality safety parameter $k_{\text {eff }}$ along the reactor cycle of a reference LFR (i.e., ALFRED reactor) has been studied, providing an exhaustive picture on the impact of nuclear data on core criticality performance and identifying nuclear data needs. Differences in sensitivities and uncertainties along burn up have been observed; however, since differences in the sensitivities are of the same order of magnitude that differences between codes and libraries, the most important isotopes and reactions for what concerns $k_{\text {eff }}$ can be considered constant along ALFRED reactor cycle. On the other hand, even if there is a good agreement between JEFF-3.3 and ENDF/B-VIII.0 nuclear data libraries for ALFRED total $k_{\text {eff }}$ uncertainty, there are significant differences in the 
contributions and the magnitude, with denote differences in the evaluations. It is important to note that there are some missing covariances in the nuclear data libraries, so differences may be higher. Furthermore, $k_{e f f}$ target accuracy is exceeded by at least a factor of two, which denotes that nuclear data must be improved to meet the target accuracies for fast reactors, such as: i) reducing the uncertainty in JEFF-3.3 ${ }^{240} \mathrm{Pu}(\mathrm{n}, \mathrm{f})$ cross section; ii) providing new covariance evaluations, such as 242Am in JEFF-3.3, and new correlations, such as ${ }^{240} \mathrm{Pu}(\mathrm{n}, \mathrm{f})-{ }^{240} \mathrm{Pu}(\mathrm{n}, \gamma)$ in the fast energy range for ENDF/B-VIII.0; and iii) identifying clearly the origin of the differences in the uncertainty evaluations.

\section{References}

[1] Generation IV International Forum, https://www. gen-4.org/gif/

[2] European Sustainable Nuclear Industrial Initiative, http://www.snetp.eu/esnii/

[3] G. Van den Eynde, E. Malambu, A. Stankovskiy, R. Fernández, P. Baeten, Journal of Nuclear Science and Technology 52, 1053 (2015)

[4] G. Grasso, C. Petrovich, D. Mattioli, C. Artioli, P. Sciora, D. Gugiu, G. Bandini, E. Bubelis, K. Mikityuk, Nuclear Engineering and Design 278, 287 (2014)

[5] R.A. Forrest, Energy Procedia 7, 540 (2011)

[6] A. Plompen, OECD/NEA JEF/DOC-1864 (2017)

[7] C. Werner, LA-UR-17-29981 (2017)
[8] P. Romojaro, F. Álvarez-Velarde, N. García-Herranz, SUMMON: A Sensitivity And Uncertainty Methodology For MONte Carlo Codes, in Proceedings of International Conference on Mathematics $\mathcal{E}$ Computational Methods Applied to Nuclear Science E Engineering (ME C 2017) (Jeju, Korea, 2017)

[9] P. Romojaro, F. Álvarez-Velarde, N. García-Herranz, Annals of Nuclear Energy 126, 410 (2019)

[10] G. Grasso, ESNII+ project D6.1.1-3 (2014)

[11] A. Gandini, G. Palmiotti, M. Salvatores, Annals of Nuclear Energy 13, 109 (1986)

[12] M.M. Bretscher, ANL/RERTR/TM-30 (1997)

[13] G. Chiba, Journal of Nuclear Science and Technology 46, 399 (2009)

[14] L. Templin, ANL-5800(2nd Ed.) (1963)

[15] P. Romojaro, F. Álvarez-Velarde, I. Kodeli, A. Stankovskiy, C.J. Díez, O. Cabellos, N. GarcíaHerranz, J. Heyse, P. Schillebeeckx, G. Van den Eynde et al., Annals of Nuclear Energy 101, 330 (2017)

[16] D.A. Brown, M.B. Chadwick, R. Capote, A.C. Kahler, A. Trkov, M.W. Herman, A.A. Sonzogni, Y. Danon, A.D. Carlson, M. Dunn et al., Nuclear Data Sheets 148, 1 (2018)

[17] M. Salvatores, G. Aliberti, M. Dunn, A. Hogenbirk, A. Ignatyuk, M. Ishikawa, I. Kodeli, A. Koning, R. McKnight, R. Mills et al., OECD/NEA Nuclear Science NEA/WPEC-26 (2008), ISBN 978-9264-99053-1 